\title{
Phase inversions observed in thermo-responsive Pickering emulsions stabilized by surface functionalized, colloidal silica
}

\section{Supporting information}

Sanna Björkegren ${ }^{a, b}$, Maria Costa Artur Freixiela Dias ${ }^{c}$, Kristina Lundahl $^{b}$, Lars Nordstierna $^{a}$ and Anders Palmqvist ${ }^{a}$

a Department of Chemistry and Chemical Engineering, Chalmers University of Technology, SE41296 Göteborg, Sweden

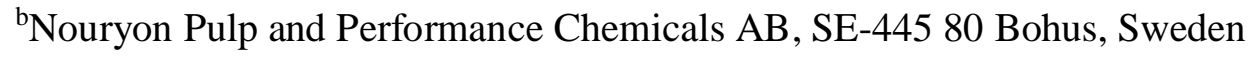

${ }^{\mathrm{c}}$ Department of Chemical Engineering, Instituto Superior Tecnico, University of Lisbon, Portugal

Number of pages: 5

Number of figures: 3

Number of tables: 3 


\section{Determination of surface coverage}

The surface coverage of sample mPEG-SiNP was known from previous work [1]. The two other silica suspensions (samples propyl-SiNPs and propyl/mPEG-SiNPs) were centrifuged at 50000 rpm or $214000 \mathrm{~g}$ for $2.5 \mathrm{~h}$ using an Optima XL-100K Ultracentrifuge from Beckman Coulter, equipped with a Type 90Ti rotor, after which a sediment (gel) of concentrated silica particles formed at the bottom of the centrifugation tubes. The supernatant, containing free, unreacted silanes and ethanol/methanol residues from the synthesis, was carefully extracted using a pipette and analysed for total carbon content using elemental analysis. Ethanol and methanol contents were obtained using high performance liquid chromatography (HPLC). The sample containing both types of silanes (propyl/mPEG-SiNP) were analysed using ${ }^{1} \mathrm{H}-\mathrm{NMR}$ spectroscopy according to previous work, to obtain the molar ratios of the free silanes in the supernatant [2]. From this, the concentrations of each silane in the supernatant were obtained and subsequently, the amounts of bound silanes could be calculated.

\section{Conductivity values of butanol in contact with salt solutions}

Table S 1. Conductivity values of butanol in contact with water and salt solution. A vial containing equal amounts of butanol and water/salt solution was shaken by hand and the conductivity of the oil phase, once it had separated, was measured at three different temperatures.

\begin{tabular}{|l|l|l|l|}
\hline \multirow{2}{*}{ Sample } & \multicolumn{4}{|l|}{ Conductivity of butanol, $\mu \mathrm{S} / \mathrm{cm}$} & At $87^{\circ} \mathrm{C}$ \\
\cline { 2 - 4 } & At $21^{\circ} \mathrm{C}$ & At $80^{\circ} \mathrm{C}$ & - \\
\hline Pure butanol & 0.05 & - & 2.7 \\
\hline $\begin{array}{l}\text { Butanol + distilled } \\
\text { water }\end{array}$ & 0.3 & 2.5 & 542 \\
\hline $\begin{array}{l}\text { Butanol }+0.3 \quad \mathrm{M} \\
\mathrm{CaCl}_{2}\end{array}$ & 50 & 430 & 280 \\
\hline Butanol + 0.3 M NaCl & 68 & 220 & \\
\hline
\end{tabular}




\section{Emulsification at fixed temperature}

The macroscopic appearance of some of the emulsions prepared, at varying $\mathrm{pH}$ conditions, salt concentrations and temperatures are given in Figure S 1. Additional micrographs (Figure S 2) and information of emulsions prepared at fixed temperatures (Table S 1) are also provided.

a)

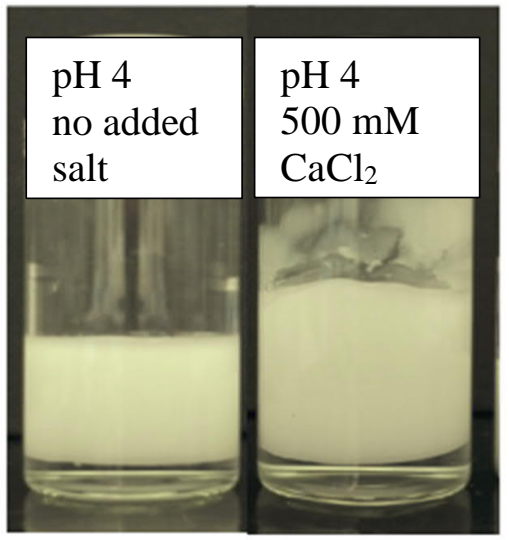

c)

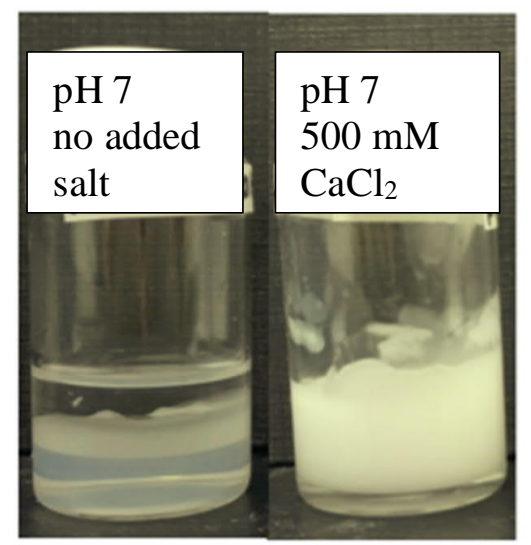

b)

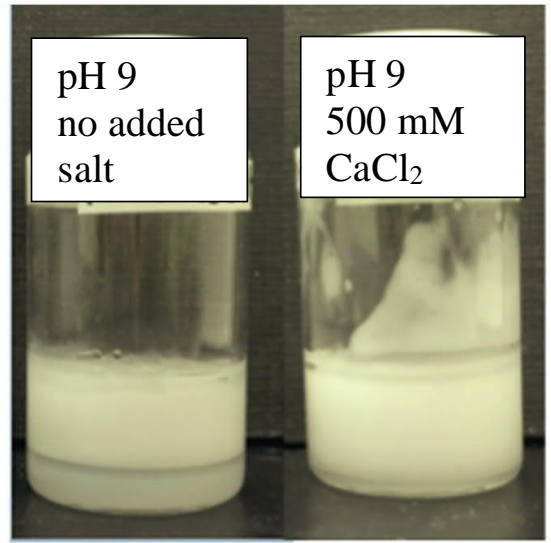

Figure S 1. Macroscopic appearance of emulsions obtained during $10 \mathrm{~min}$ emulsification around $45^{\circ} \mathrm{C}$, of butanol in water, at different $\mathrm{pH}$ conditions and salt concentrations of the aqueous phase, containing the stabilizing propyl/mPEG-SiNPs. a): pictures captured two weeks after emulsification, b): pictures captured one week after emulsification and c): pictures captured the day of emulsification. 

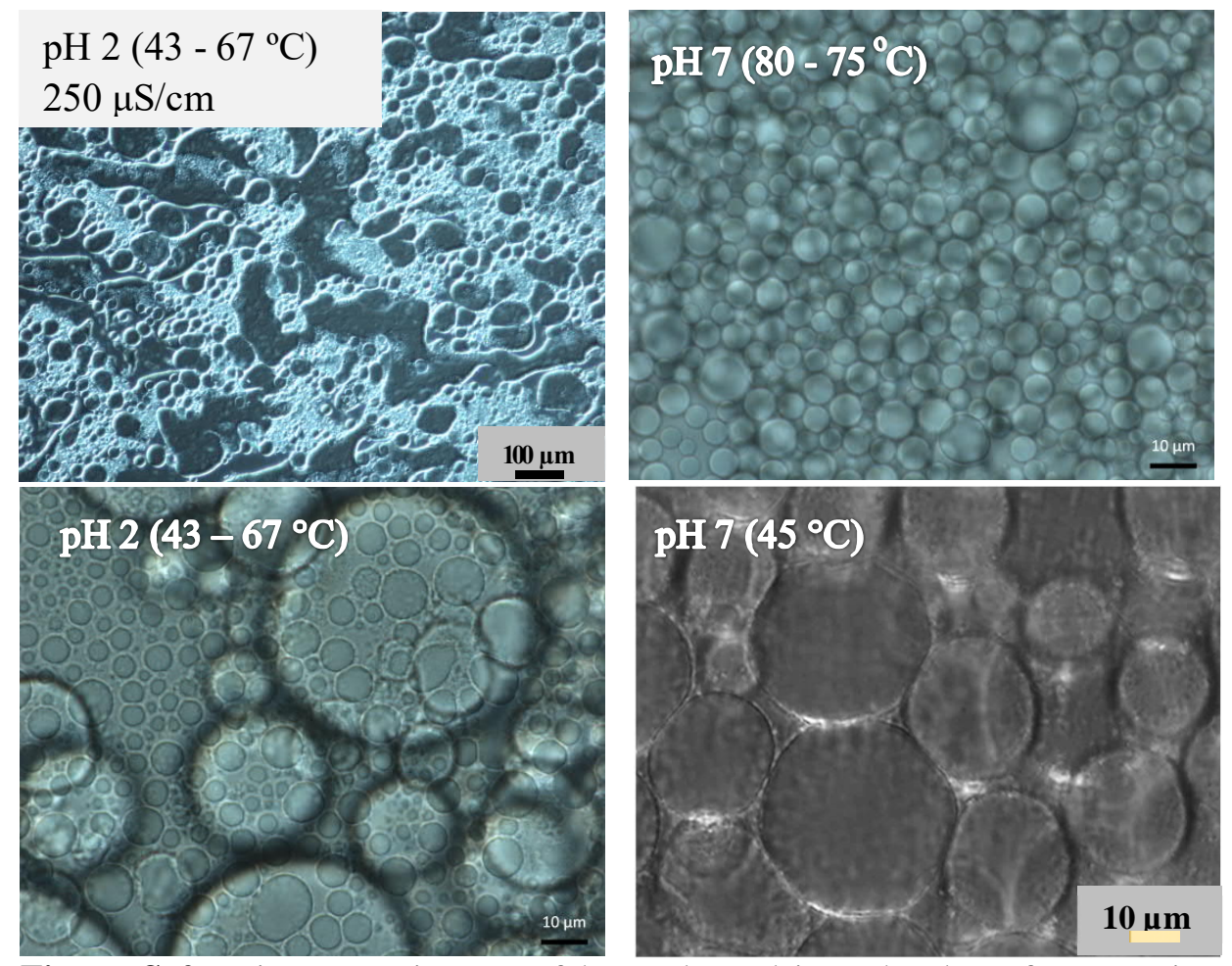

Figure S 2. Microscope images of butanol emulsions the day of preparation, emulsified at varying temperatures and $\mathrm{pH}$ conditions using propyl/mPEG-SiNP as emulsifier. The scale bar represents $10 \mu \mathrm{m}$. The temperatures provided in the brackets are $T_{\text {start of emulsification }}-T_{\text {end of emulsification. }}$

Table S 2. Examples of emulsions prepared at fixed temperatures, emulsified for 10 minutes through homogenization at $12000 \mathrm{rpm}$, at varying $\mathrm{pH}$ conditions.

\begin{tabular}{|l|l|l|l|l|l|}
\hline \multicolumn{2}{|c|}{ Emulsions prepared without added salt } \\
\hline $\begin{array}{l}\text { Emulsion } \\
\text { conditions }\end{array}$ & $\begin{array}{l}\text { Emulsification } \\
\text { temperature } \\
\left({ }^{\circ} \mathrm{C}\right)\end{array}$ & $\begin{array}{l}\text { Expected } \\
\text { PIT }\left({ }^{\circ} \mathrm{C}\right)\end{array}$ & $\begin{array}{l}\text { Conductivity, } \\
\text { aqueous phase } \\
(\mu \mathrm{S} / \mathrm{cm})\end{array}$ & $\begin{array}{l}\text { Conductivity, } \\
\text { cooled } \\
\text { emulsion } \\
(\mu \mathrm{S} / \mathrm{cm})\end{array}$ & $\begin{array}{l}\text { Phase } \\
\text { appearance }\end{array}$ \\
\hline pH 2 & $43-67$ & 48 & 3050 & 250 & w/o unstable \\
\hline pH 7 & $75-80$ & 92 & 770 & 300 & $\begin{array}{l}\text { o/w, small, } \\
\text { close-packed } \\
\text { droplets }\end{array}$ \\
\hline
\end{tabular}

\section{Reversibility and hysteresis effects}

Figure S 3 shows the hysteresis at two different cooling rates: 1) cooled during 5 minutes in a water-bath and 2) cooled slowly in an oil-bath during 2 hours. The results point to no direct effect of the rate of cooling. 


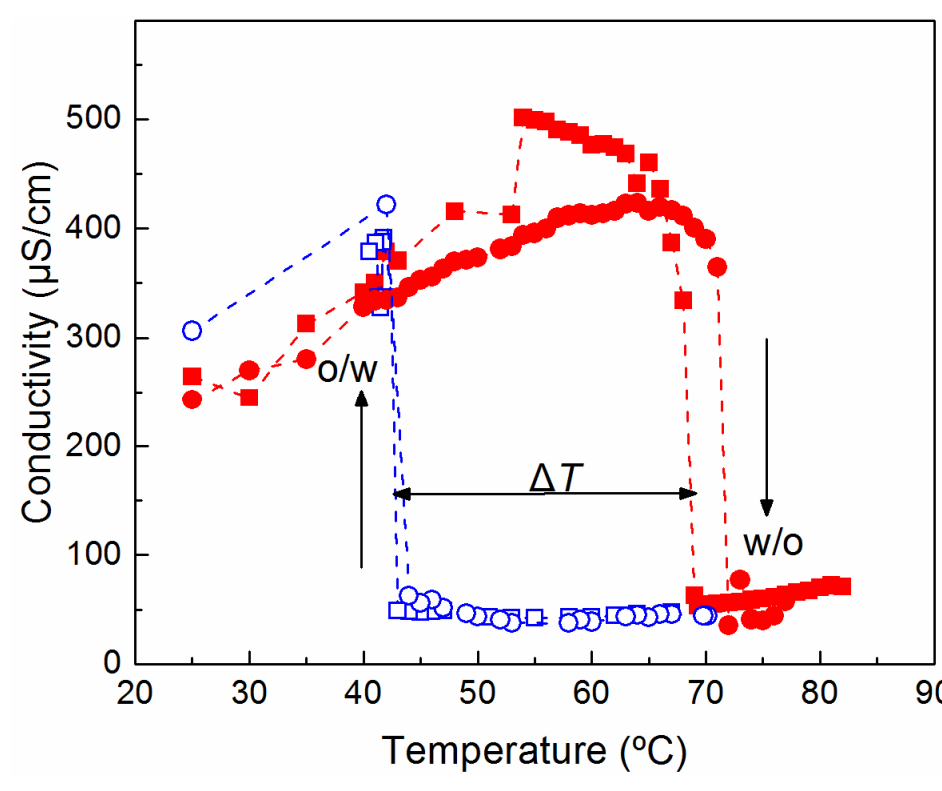

Table S 3 shows the observed PIT values where the inversion from o/w to w/o occurs, the temperatures at which the emulsions switch back to w/o and the hysteresis effect $\Delta T$, at varying $\mathrm{pH}$ and salt contents of some of the emulsion systems studied.

Table S 3. PIT values (inversion o/w to w/o), temperatures at which the emulsions switch back to w/o and the hysteresis effect at varying salt contents and $\mathrm{pH}$. The values at $\mathrm{pH} 4$ are averages from 2-4 experiments, and the uncertainty increases with the salt concentration.

\begin{tabular}{|l|l|l|l|l|}
\hline $\begin{array}{l}\text { Salt concentration } \\
\left(\mathrm{mM} \mathrm{CaCl}_{2}\right)\end{array}$ & $\begin{array}{l}\mathrm{pH} \text { of } \\
\text { aqueous } \\
\text { phase }\end{array}$ & $\begin{array}{l}\text { PIT, } \\
\text { inversion to w/o }\left({ }^{\circ} \mathrm{C}\right)\end{array}$ & $\begin{array}{l}\text { Switch back PIT, } \\
\text { inversion to o/w }\left({ }^{\circ} \mathrm{C}\right)\end{array}$ & $\Delta T^{*}\left({ }^{\circ} \mathrm{C}\right)$ \\
\hline \multirow{3}{*}{ No added salt } & 2 & 48 & 43 & 5 \\
\cline { 2 - 5 } & 4 & 76 & 45 & 31 \\
\cline { 2 - 5 } & 7 & 92 & 60 & 32 \\
\hline \multirow{3}{*}{100} & 2 & 48 & 42 & 26 \\
\cline { 2 - 5 } & 4 & 62 & 36 & 16 \\
\cline { 2 - 5 } & 7 & 72 & 56 & 16 \\
\hline \multirow{3}{*}{500} & 2 & 40 & 35 & 17 \\
\cline { 2 - 5 } & 4 & 51 & 35 & 50 \\
\cline { 2 - 5 } & 7 & 67 & $\mathrm{ing}$ & 6 \\
\hline
\end{tabular}

* Difference between PIT (inversion o/w to w/o) and switching back temperature (inversion w/o to $\mathrm{o} / \mathrm{w}$ )
Figure S 3. Conductivity as a function of temperature during emulsification of butanol in an aqueous phase adjusted to $\mathrm{pH} 4$, with 0.1 $\mathrm{mM} \mathrm{CaCl} 2$ and containing propyl/mPEGSiNPs which act as emulsifiers. The system was first heated during the homogenization (red solid symbols) and after the PIT had been observed the system was cooled with the homogenization running to achieve inversion back to o/w emulsions (blue open symbols). which occurs during heating of the system, and from w/o back to $\mathrm{o} / \mathrm{w}$, occurring while cooling. The hysteresis, $\Delta T$, is the difference between inversion from o/w to w/o and w/o to $\mathrm{o} / \mathrm{w}$. The w/o emulsion was cooled with different rates; 2 hours (heating: red $\bullet$, cooling: blue $\odot$ ) and five minutes (heating: red $\square$, cooling: blue $\square$ ). The arrows indicate inversion from $\mathrm{o} / \mathrm{w}$ to $\mathrm{w} / \mathrm{o}$, 


\section{References}

1. Björkegren, S.M.S., L. Nordstierna, A. Törncrona, M.E. Persson, and A.E.C. Palmqvist, Surface activity and flocculation behavior of polyethylene glycol-functionalized silica nanoparticles. Journal of Colloid and Interface Science, 2015. 452(0): p. 215-223.

2. Björkegren, S., L. Nordstierna, A. Törncrona, and A. Palmqvist, Hydrophilic and hydrophobic modifications of colloidal silica particles for Pickering emulsions. Journal of Colloid and Interface Science, 2017. 487: p. 250-257. 